\title{
Construction of project portfolio considering efficiency, strategic effectiveness, balance and project interdependencies
}

\author{
BarisCanbaz, Franck Marle* \\ Ecole Centrale Paris, \\ Laboratoire Genie Industriel, \\ Grande voie des vignes, \\ 92295 Chatenay-Malabry, France \\ E-mail: franck.marle@ecp.fr \\ *Correspondingauthor
}

\begin{abstract}
This paper aims at providing project office managers or portfolio-level decisionmakers with an integrated methodology to guide the portfolio selection process.

The issue is to define a selection algorithm which is simultaneously built on a sound theory and remains practically manageable. The originality is to integrate project interdependencies at different levels, both in the objective function (both inputs and outputs) and in the definition of new constraints that ensure the portfolio balance and effectiveness. The portfolio construction problem is formalized and resolved with Constraint Satisfaction Problem techniques. We show on a numerical fictitious example that results are significantly different considering or not project interdependencies. Some portfolios may be declared unfeasible and excluded from decision alternatives, and key values, like global revenue, may drastically change because of synergies or cannibalizations between projects. Our approach improves the performance of portfolios and increases the accuracy forecast between the expected outcomes and the actual ones, since interdependencies are modelled in a way which is closer from reality.
\end{abstract}

Keywords

Project management; Project portfolio selection; Project interactions; Nonlinear programming; Constraints satisfaction

\section{Introduction}

While project management is a process that focuses on the extent to which a specific and temporary endeavor establishes, maintains and achieves its intended targets within cost, time, and performance parameters, project portfolio management focuses attention at a more aggregated level. Its primary objective is to build and maintain the appropriate mix of projects necessary to achieve organizational goals, with a short-term or long-term range. A portfolio may mix projects of different natures, of different sizes and of different status (from $0.1 \%$ to $99.9 \%$ of advancement). Portfolio-level decisions are crucial since they affect strategic effectiveness, resource allocation efficiency and balance at a portfoliolevel rather than at a project-level perspective (Floricel \& Ibanescu 2008; Petit 
2012; Killen et al. 2012; Kester et al. 2011). This means that the success of the portfolio may imply to stop or to postpone a project, which does not contribute to the success of this project, but the stakes and the decision level are higher.

PPM is of growing importance, particularly for project-based organizations (Maylor et al. 2006; Thiry \& Deguire 2007), and particularly in two domains strongly addressed in literature:

- the Information Systems projects (J. W. Lee \& Kim 2001; C.-T. Chen \& H.-L. Cheng 2009; Santhanam et al. 1989; Schniederjans \& Santhanam 1993; Lucas \& Moore 1976; Bacon 1992; Bardhan et al. 2004)

- the R\&D projects (R. Cooper et al. 1998; R. G. Cooper et al. 1998; R. G. Cooper, E. S. Edgett, et al. 1997; R. G. Cooper, S. J. Edgett, et al. 1997; Lockett \& A. E. Gear 1973; Hall \& Nauda 1990; Mikkola 2001).

Consideration of complexity in PPM is also of growing importance, for two reasons: projects are becoming more and more complex, and portfolios may include numerous projects, linked by numerous interdependencies, making themselves complex portfolios. This involves developing and implementing models that consider complexity, both at project and portfolio-levels, particularly in project selection.

This paper aims at improving the performance of project portfolios by selecting and executing the right combination of projects while taking into account their interdependencies. The remainder of the paper is as follows. Section 2 introduces challenges for PPM considering project interdependencies. Extensive literature review on project portfolio selection is introduced in Section 3. The mathematical problem is formulated in Section 4 with a particular focus on integration of project interdependencies. Section 5 describes the strategy to solve the problem. Section 6 presents the application of the model on a fictitious example and conclusions are drawn in Section 7.

\section{Challenges for PPM research}

Consequence of complexity is a potential distortion in assessment and prediction of project attributes and interdependencies. This is an important issue since choosing the right combination of projects may help to obtain more value than the sum of individual projects, because of positive interactions (called synergies), or less value in case of negative interactions (called cannibalizations). Organizations therefore need to pay more attention to managing the mix of various projects to avoid negative interactions among the projects and to benefit from possible positive interactions. Historically, many PPM tools and techniques treated each project as an isolated entity, despite the gap with reality and despite the existence of literature for decades (Reiter 1963; Aaker \& Tyebjee 1978; T. E. Gear \& Cowie 1980).

Several difficulties are associated with project portfolio selection (Kerzner 2004; Ghasemzadeh 1998). Firstly, the inclusion of a project and its input and output values may be dependent on the other projects in the same portfolio. For instance, when projects share the same resource (human or material), the resource requirements of projects may be reduced if they are included together in 
the portfolio. Interactions can also be negative when there are cannibalizations between projects in the same portfolio, in terms of market share for instance. Projects may be mutually exclusive, which means that they cannot simultaneously exist in the portfolio. On the other hand, mutually inclusive projects cannot be started without the inclusion of the other projects in the portfolio. Determination of these interactions and interdependencies, in terms of existence and value, is an extremely complex process.

Secondly, random and epistemic uncertainties are inherent to the evaluation data of a project, due to the stochastic nature of the project activity and its environment, and because evaluation is undertaken before the project starts. In reality, everything is potential and some criteria may sometimes be evaluated years before they occur, like the final profit or the final cost for instance.

Thirdly, variables may be qualitative or quantitative, and it is difficult to get a global evaluation by mixing different kinds of data (for example, mixing the image of the organization with the expected long-term profit and with the improvement of customer satisfaction). This requires some work to calibrate the evaluation scales in order to make them comparable.

Lastly, the portfolio may need to be balanced. Some zones have to be defined in order to analyse the balance in terms of number of projects in each of them. There are two key points when studying balance: zones must be correctly defined, and particular attention must be paid to projects which are close to a frontier.

\section{Literature review on project portfolio selection}

From the beginning of the development of the subject, numerous project selection tools and approaches have been proposed, as this activity being recognized as critical (Guimaraes \& McKeen 1988; McKeen \& Guimaraes 1985; Melone \& Wharton 1984; Santhanam \& Schniederjans 1993). We divide these various tools into four categories: portfolio mapping tools, multi-criteria ranking tools, mathematical programming tools and hybrid tools (Hall \& Nauda 1990; R. Cooper et al. 1998).

\subsection{Portfolio mapping tools}

As introduced in previous Section, portfolio mapping tools are generally simple, two-axis diagrams that easily display the trade-off between two criteria (Dickinson et al. 2001; Mikkola 2001). Assessment may be qualitative or quantitative, precise or imprecise. The use of bubbles instead of points has the advantage of adding complementary information illustrated with the size, color and shape of the bubble (R. G. Cooper, E. S. Edgett, et al. 1997; R. G. Cooper, S. J. Edgett, et al. 1997). These tools use graphical and charting techniques to help to prioritize projects (depending on their position on the graph) and to estimate the balance of the portfolio (the number of projects in each zone of the graph). This supposes that the criteria used for mapping has been previously defined, as well as their evaluation scale (ordinal, cardinal, quantitative...) and the different 
Author

zones for interpretation of the position of the project. Interdependencies between projects are sometimes considered (Groenveld 1997; Killen 2012).

\subsection{Multi-criteria decision-making tools}

Multi-criteria decision-making tools include scoring and ranking/sorting models. These methods maximize the value of the portfolio with both financial and/or non-financial measures. With scoring models, projects are assessed on a number of different criteria that can be weighted regarding their importance (Moore \& N. R. Baker 1969; Lucas \& Moore 1976; Henriksen \& Traynor 1999; Jiang \& Klein 1999; Lootsma et al. 1990; Shoval \& Luhasi 1987).

Ranking and outranking methods propose a respectively absolute or relative ranking of alternatives (Buss 1983; Odusote \& Fellows 1992). For instance, Analytic Hierarchy Process (T. Saaty 1980; T. L. Saaty 2001) and the Electre family(Roy 1991; Figueira et al. 2009; Doumpos et al. 2009; Skitmore et al. 2001) are multi-criteria scoring/ranking methods that use hierarchical criteria and pair wise comparisons. AHP has been particularly used in numerous research works, including some refinements and variations around the initial version of the method (Muralidhar et al. 1990; Al Khalil 2002; Brenner 1994; Mohanty 1992; Alidi 1996; Xidonas et al. 2009; Gerogiannis et al. 2010).

Generally, refinements consist of including interdependencies using the Analytic Network Process (E. W. L. Cheng \& Li 2005; Meade \& Presley 2002; Aragonés-Beltrán et al. 2010; J. W. Lee \& Kim 2001) or introducing uncertainty using fuzzy numbers (Mahmoodzadeh et al. 2007; C. C. Huang et al. 2008; Tiryaki \& Ahlatcioglu 2009; Büyüközkan \& Feyzioglü 2004). The checklist method is a variation on the scoring model with multiple criteria in multiple categories assessed with a yes/no answer based on a minimum threshold acceptance value (R. G. Cooper et al. 1998).

\subsection{Mathematical programming}

Mathematical models developed for portfolio selection focused historically on maximizing the financial portfolio value within some budget constraints (N. R. Baker 1974; Danila 1989; Liberatore \& Titus 1983; Pillai et al. 2002). They focused mainly on quantitative tools and values, like cash flow, net present value or return on investment or payback period (Liberatore 1987; Okpala 1991; Weingartner 1966b).

In order to overcome limitation of such models and of some multi-criteria decision-making models (the compensatory bias), some mathematical programming models have been introduced, such as goal programming (S. Lee 1972; Benjamin 1985; Badri et al. 2001; Santhanam et al. 1989; Khorramshahgol et al. 1988; Gori 1996), multi-objective or multi-attribute decision-making (G. Hwang \& Yoon 1981; Schniederjans \& Santhanam 1993; Anadalingam \& Olsson 1989; Ringuest \& Graves 1989; Molenaar \& Songer 1998), quadratic or nonlinear programming (Weber et al. 1990; Santhanam \& Kyparisis 1995) and dynamic programming (Ullmann 1967; Nemhauser \& Ullmann 1969). 
Like in multi-criteria methods, uncertainty is often modeled through the fuzzy set theory (K. Chen \& Gorla 1998; C.-T. Chen \& H.-L. Cheng 2009; J. Wang \& W. L. Hwang 2007; Machacha \& Bhattacharya 2000; Coffin \& Taylor 1996; Wong et al. 2000; Carlsson et al. 2007; X. Huang 2007; Ghapanchi et al. 2012; Iyigun 1993; Tiryaki \& Ahlatcioglu 2005; Lin \& Hsieh 2004; Zhu et al. 2009). Some models do not need computational support to make calculations, like decision trees and game theory techniques (Hess 1993; Ali et al. 1993).

Data Envelopment Analysis (DEA) helps select the best portfolio taking both project uncertainties and projects interdependencies into consideration simultaneously (Eilat et al. 2006). Classically, fuzzy DEA (FDEA) is an extension considering a particular way to model uncertainty on data (Ghapanchi et al. 2012).Generally, all of these models not direct attention to balancing the portfolio. Recent developments enrich the parameters considered for optimizing the portfolio (Liesiö et al. 2007; Eilat et al. 2006).

\subsection{Hybrid decision-making tools}

Hybrid decision-making tools are combinations of a number of different tools (Conka et al. 2008; Sun \& Ma 2005; Riddell \& Wallace 2011). For instance, AHP is mixed with goal programming (Schniederjans \& Wilson 1991) or multiattribute decision-making (Dey 2006). A mix of different techniques for considering uncertain and imprecise assessments and project interdependencies has been proposed (Ravanshadnia et al. 2010). The Contingent Portfolio Programming is a combination of decision trees and mathematical programming (Gustafsson \& Salo 2005). A similar model existed before (Lockett \& A. E. Gear 1973), but CPP integrates new dimensions like uncertainties with certainty equivalencies, and the support of multiple additive decision criteria regarding the staged nature of R\&D projects.

\section{Problem formulation}

4.1. Modelling and integrating project interdependencies

The challenge of managing multiple complex projects in a dynamic and uncertain environment is amplified by the presence of project interdependencies, which are simultaneously crucial for reliable decisions and difficult to capture and pre-dict (Aritua, N. J. Smith, and Bower 2009; Blau et al. 2004; Collyer and Warren 2009; Dahlgren and Söderlund 2010; Elonen and Artto 2003; Perminova, M. Gustafsson, and Wikström 2008; Rungi 2010; Verma and Sinha 2002).Focus is made here on project interdependencies consideration, as Baker and Freeland and more recently Eilat and co-authors underlined the weaknesses of these portfolio selection models and criticized them (N. Baker \& Freeland 1975; Eilat et al. 2006): "one of the most important limitations of present R\&D project selection models is the inadequate treatment of project interrelationships with respect to both value and resource utilization."

Several types of project interdependencies exist and have been introduced in previous works (Dickinson, Thornton, and Graves 2001; T. E. Gear and Cowie 1980; Killen and Kjaer 2012; Newell et al. 2008; Verma and Sinha 2002). The 
originality of our contribution is to consider simultaneously four types of interactions between projects, in terms of outcomes, of resource consumption, of probability of success and of mutual inclusion/exclusion. Resource may include human, material and financial resources. The benefit interdependency may be considered by different ways, for instance complementary or competitive effects on market shares. Here, it is a combined probability of success if both projects are run simultaneously which is considered. A fifth type of interdependency is called learning dependency: "the need to incorporate the capabilities and knowledge gained through another project" (Killen and Kjaer 2012).

Like project attributes, interdependencies are by nature difficult to assess, since even their existence is sometimes potential, meaning that we have a potential chance to have interdependency between two projects with an uncertain value. This makes all the more difficult the introduction of project interdependencies into exact calculation models. The results should be analysed considering the error or uncertainty on data, meaning that the gap between two proposed solutions should be superior to the error margin to be considered reliable enough to make a decision.

Several methods have included project interdependencies in the portfolio selection problem formulation (Czajkowski \& Jones 1986; Weingartner 1966a; J. W. Lee \& Kim 2001; Reiter 1963; Aaker \& Tyebjee 1978; Santhanam \& Kyparisis 1996). Schmidt presents three different types of interactions in his portfolio construction model (Schmidt 1993). It combines the effects of resource interactions, benefit interactions and outcome interactions among projects. These interactions are represented with matrices. The combined effect of these different interactions among projects was initially considered by Aaker and Tyebjee, but they did not define an objective function and they did not construct a methodology for solving the problem (Aaker \& Tyebjee 1978).

Dickinson and co-workers presented a real world application of portfolio management process at Boeing Company (Dickinson et al. 2001). The proposed method accounts for revenue interactions among projects with a dependency matrix which is constructed with qualitative assessments. An objective function maximizes the net present value of the entire portfolio. The model contains constraints about resource budget, about the maximum number of projects in a portfolio and about the minimum number of projects that must support each of the strategic objectives of the program. One project can support only one strategic objective.Liesiö and co-workers extended their Robust Portfolio Modelling technique (Liesiö et al. 2007) to account for project interactions (Liesiö et al. 2008). Interactions among projects are represented with dummy projects that are triggered by synergy and cannibalization constraints. However, these constraints do not contain the combined effect of different type of interactions that Schmidt considered.

Schmidt's approach is the most complete one in terms of its description and formulation of project interactions. Considering the three portfolio objectives (Efficiency, Balance, and Strategic Effectiveness), all approaches maximize the portfolio efficiency. Dickinson and co-workers support portfolio balance with 
graphical tools. Liesiö and co-workers provide portfolio balance more effectively with logical constraints. Regarding the strategic effectiveness of a portfolio, Schmidt's approach does not support this portfolio objective except with budget constraints. Since there is no complete method which satisfies the entire project portfolio construction objectives while integrating the combined effect of different interactions among the projects, we combined the strongest aspects of these models with additional features.

This Section introduces our formulation proposal, including objective function and numerous constraints. The strength of this proposal is the introduction of useful and feasible constraints, meaning that they have an influence on the performance of the final proposed portfolio (influencing parameter), but simultaneously they make sense for practitioners and are feasible in terms of assessment (precision and energy to get the data).

\subsection{Nomenclature}

\begin{tabular}{|c|c|}
\hline$R$ & total number of outputs \\
\hline I & total number of inputs \\
\hline$x_{i}$ & amount of input $i$ required for the portfolio \\
\hline$y_{r}$ & amount of output $r$ expected from the portfolio \\
\hline$z$ & $\begin{array}{l}n_{p} \text {-digit vector, its binary elements represent the selection of the } \\
\text { corresponding project in the portfolio. If the project } j \text { is included in the } \\
\text { portfolio then its corresponding value } z_{j} \text { is } 1 \text {, otherwise } z_{j}=0\end{array}$ \\
\hline$z^{k}$ & $\begin{array}{l}\text { Vector that represents the selection of the projects in the alternative } \\
\text { portfolio } k \text {. If the project } j \text { is included in the portfolio } \mathrm{k} \text { then } z_{j}^{k}=1 \text {, } \\
\text { otherwise } z_{j}^{k}=0\end{array}$ \\
\hline$n_{p}$ & total number of projects \\
\hline $\operatorname{Max}$ & maximum number of projects limit of the portfolio \\
\hline Min & minimum number of projects limit of the portfolio \\
\hline $\operatorname{Max}_{j}$ & $\begin{array}{l}\text { maximum number of projects limit of the portfolio dependent on } \\
\text { project } j\end{array}$ \\
\hline $\operatorname{Min}_{j}$ & $\begin{array}{l}\text { minimum number of projects limit of the portfolio dependent on project } \\
j\end{array}$ \\
\hline$S_{j o}$ & score of the project $j$ for objective $o$ \\
\hline MinScore $_{o}$ & minimum score that must be obtained for objective $o$ \\
\hline$R_{i}$ & resource budget for the input $i$ \\
\hline$Q_{r}$ & minimum expectancy threshold of the output $r$ \\
\hline$U^{i}$ & resource interaction matrix of input $i$ \\
\hline$V^{r}$ & benefit (value of direct output) interaction matrix of output $r$ \\
\hline$P$ & probability of success interaction matrix \\
\hline$D_{j}$ & Domain of the variable $z_{j} \cdot D_{j}=\{0,1\}, \forall j=1 \cdots n_{p}$ \\
\hline
\end{tabular}




\subsection{Objective function}

Three main dimensions are considered for portfolio selection:

- Efficiency: the goal is to maximize a value which is often defined by profitability or some other financial measure, relating outcomes to resources used to obtain them.

- Balance: the portfolio can be balanced in dimensions such as long-term vs. short-term, low risk vs. high risk and breakdown by project types or market areas.

- Strategic Effectiveness: investments should contribute to corporate objectives. For example, even a highly profitable investment can be turned down if it does not relate to core competencies of the firm.

It is possible to run a multi-objective optimization or to focus on a specific objective and consider the two other parameters as constraints. We decide to use the latter form and generate the portfolio which has the maximal efficiency value while not violating the constraints of balance and strategic effectiveness.

A portfolio is defined as a binary vector $z$, which indicates for each project whether it belongs or not to the portfolio. The efficiency value of the portfolio refers to its expected revenue which is the difference between the total expected output $y$ of the portfolio and the total input $x$ invested into the portfolio, where inputs are both variable and fixed costs. The aim of the objective function is to maximize the expected revenue of the portfolio:

$\operatorname{Max}($ Revenue $)=\sum_{\mathrm{r}=1}^{\mathrm{R}} \mathrm{y}_{\mathrm{r}}-\sum_{\mathrm{i}=1}^{\mathrm{I}} \mathrm{x}_{\mathrm{i}}$

The interactions handled in this methodology are considered for pairs of projects. They consider the marginal effect of the selection or rejection of a project on the other projects in the portfolio. External interactions may appear over time due to social, political and economic changes, but are not considered in this study. Interactions among projects will change the amount of inputs required during the execution of the portfolio and the amount of expected outputs generated with this execution. These interactions are resource interactions, benefit interactions, and outcome interactions, following previous works (Schmidt 1993; Fox et al. 1984; Eilat et al. 2006). Input values, output values, resource interactions and benefit interactions should be scaled with the same unit of measurement; this can be a common financial unit or a qualitative score.

Benefit interactions occur if the total amount of the benefits (direct outputs) of interacted projects which are executed simultaneously is different from the situation in which the projects are executed individually. If the projects are complementary, this difference is positive (synergy effect); if they are competitive, then the difference is negative (antagonism). $\boldsymbol{V}^{r}$ is the benefit (value of direct output) interaction matrix of output $r$ which is a lower triangular matrix $\left(v_{\mathrm{kj}}^{\mathrm{r}}=0, \mathrm{ifj}>k\right)$. The diagonal element of this matrix $\mathrm{v}_{\mathrm{jj}}^{\mathrm{r}}$ represents the amount 
of direct output $r$ from the individual project $j$ and the off-diagonal element $v_{\mathrm{ij}}^{\mathrm{r}}$ represents the benefit interaction of output $r$ between projects $i$ and $j$.

Outcome interactions occur if the probability of success of a project changes by undertaking another project in the same portfolio. This interaction reflects the relationship among the project successes. $P$ is the probability of success interaction matrix. The diagonal element $\mathrm{p}_{\mathrm{jj}}$ is the probability of success of project $j$ and the off-diagonal element $\mathrm{p}_{\mathrm{jk}}$ represents the probability of success interaction among two projects, which is the marginal change in the probability of success of the project $j$ when project $k$ is included in the portfolio. In general, $\boldsymbol{P}$ matrix is neither symmetrical nor triangular, because the reciprocal impacts can be different; project $j$ may have greater impact on project $k$ than vice versa. The detailed formulation of the amount of output expected from the portfolio is thus given by:

$\mathrm{y}_{\mathrm{r}}=\sum_{\mathrm{j}=1}^{\mathrm{n}_{\mathrm{p}}} \mathrm{z}_{\mathrm{j}}\left(\sum_{\mathrm{l}=1}^{\mathrm{n}_{\mathrm{p}}} \mathrm{z}_{\mathrm{l}} \mathrm{p}_{\mathrm{jl}}\right)\left[\mathrm{v}_{\mathrm{jj}}^{\mathrm{r}}+\sum_{\mathrm{i}=1}^{\mathrm{j}-1} \mathrm{v}_{\mathrm{ji}}^{\mathrm{r}} \mathrm{z}_{\mathrm{i}}\left(\sum_{\mathrm{l}=1}^{\mathrm{n}_{\mathrm{p}}} \mathrm{p}_{\mathrm{il}} \mathrm{z}_{\mathrm{l}}\right)\right]$ for $\forall \mathrm{r}$

$\mathrm{j}, \mathrm{l}, \mathrm{i}, \mathrm{h} \in \mathbb{Z}$

$\mathrm{z}_{\mathrm{j}} \in \mathrm{D}_{\mathrm{j}}, \quad \forall \mathrm{j}=1 \cdots \mathrm{n}_{\mathrm{p}}$

Resource interactions occur if the total resource requirements of a project portfolio cannot be represented as the sum of its individual project requirements. It occurs when the projects share the same resources, where portfolio resource requirements are less than the sum of individual project requirements. $U^{\mathrm{i}}$ is defined as the resource interaction matrix of input $i$. This is a lower triangular $\operatorname{matrix}\left(\mathrm{u}_{\mathrm{kj}}^{\mathrm{i}}=0\right.$, if $\left.\mathrm{j}>k\right)$. The diagonal element $\mathrm{u}_{\mathrm{jj}}^{\mathrm{i}}$ represents the amount of input $i$ that is required for the individual project $j$ and the off-diagonal element $\mathrm{u}_{\mathrm{kj}}^{\mathrm{i}}$ represents the resource interaction of input $i$ between projects $j$ and $k$.The detailed formulation of the amount of input $i$ required for the portfolio is thus given by:

$x_{i}=\sum_{j=1}^{n_{p}} z_{j} u_{j j}^{i}+\sum_{j=1}^{n_{p}} \sum_{h=j+1}^{n_{p}} z_{j} z_{h} u_{h j}^{i}$ for $\forall i$

$\mathrm{j}, \mathrm{l}, \mathrm{i}, \mathrm{h} \in \mathbb{Z}$

$\mathrm{z}_{\mathrm{j}} \in \mathrm{D}_{\mathrm{j}}, \quad \forall \mathrm{j}=1 \cdots \mathrm{n}_{\mathrm{p}}$

The CSP requires a solution that maximizes the objective function. Variables of the CSP are $: z_{j} \forall j=1 \cdots n_{p}$. All of the variables are binary so the domains of the variables include only 0 and $1, D_{j}=\{0,1\}, \forall j=1 \cdots n_{p}$. Constraints of the CSP are described hereunder.

\subsection{Portfolio Balance Constraints}

We define balance constraints in order to control which projects must be executed together and which must not be executed together in the same portfolio. For instance, two very risky projects should not be launched simultaneously, since they may both fail. If they share the same market or the same scarce 
resource, we would prefer not to undertake them together. On the other hand, it is possible to decide that a project cannot be started without starting another one, or that they can be complementary. It might be more efficient to fund these two projects simultaneously.

With these balance constraints, we can control the diversification of the projects in the portfolio in terms of various trade-offs. This helps to build balanced portfolios and to express constraints of mutual exclusion or mutual inclusion. For example, if project 3 must always be included when project 1 is already in the portfolio, then the related constraint is conditional:

$I F z_{1}=1 T H E N z_{1}+z_{3}=2$

If project 5 and project 2 are mutually exclusive projects and project 5 and project 3 likewise, only one of these projects can be selected. The related constraint is:

$\mathrm{IF} z_{5}=1 \quad T H E N z_{5}+z_{2}+z_{3}=1$

Portfolio Strategic Effectiveness Constraints described hereunder will guarantee economic fit, strategic fit and feasibility of the portfolio.

\subsection{Portfolio Size Constraints}

Organizations could have preferences on maximum and/or minimum number of projects in a single portfolio, this defines portfolio size limits. For example, they can prefer the portfolios which have equal or less than a given number of projects, since the portfolios which have more projects than this limit would be too complex to be executed by the organization and outside the feasibility limits. Thus, organizations would like to define the maximum number of projects in a portfolio to maintain the portfolio feasible and to avoid funding very complex portfolios.

As well as defining maximum number of projects in a portfolio, organizations can also define the minimum number of projects in a single portfolio. They can stipulate that each portfolio must have equal or more than a given number of projects, since the portfolios which do not contain enough projects generally do not provide enough profit and do not benefit from synergies between projects. The definition of the maximum and minimum number of projects in a portfolio will support effectiveness, and this will help organizations to align the mix of projects in the portfolio with organizational needs and limits.

$\sum_{\substack{j=1 \\ n_{p}}}^{n_{p}} z_{j} \leq \operatorname{Max}$
$\sum_{j=1}^{z_{j}} z_{j} \geq \operatorname{Min}$

Portfolio size limits can also be dependent on portfolio elements, namely the projects which are selected in the portfolio. For example, if a project is very complex, an organization can consider having a maximum limited number of other projects in a portfolio with this project. An organization wants to maintain feasibility, otherwise the portfolio will be so complex to handle that it will no 
longer be feasible. An organization can also consider a project too simple to be executed with less than a minimum number of other projects.

$$
\begin{gathered}
I F z_{j}=1 \text { THEN } \sum_{\substack{j=1 \\
n_{p}}}^{n_{p}} z_{j} \leq \operatorname{Max}_{j} \text { for } \forall j \\
I F z_{j}=1 \text { THEN } \sum_{j=1}^{z_{j}} z_{j} \geq \operatorname{Min}_{j} \text { for } \forall j
\end{gathered}
$$

While Max and Min define the limits of maximum and minimum number of projects in the portfolio for any combination of the projects regardless of the projects in the portfolio and their characteristics, $\operatorname{Max}_{j}$ and $\operatorname{Min}_{j}$ determine the limits of the size of the portfolio for a particular project $j$ included in this portfolio.

\subsection{Input and Output Threshold Constraints}

Projects use different type of input to create different type of output. In general, these inputs are limited and the organization has minimum output expectancies. Therefore, a selection model that incorporates resource limitations may aid the decision maker. Typically, an organization is not able to simultaneously engage more than a certain quantity of inputs, called $\mathrm{R}_{\mathrm{i}}$. It would like to obtain at least a certain amount of outputs from their project portfolios, called $\mathrm{Q}_{\mathrm{r}}$, otherwise they find it worthless to undertake.

$x_{i} \leq R_{i}$

$y_{r} \geq Q_{r}$

\subsection{Strategic Objective Constraints}

Every organization aims to link the project portfolio to its business strategy and to its general strategic objectives. The main focus is to ensure that the final portfolio truly reflects the strategy of the company. In order to maintain this alignment of the portfolios with organizational strategy, we use a projectobjective contribution score matrix, called S. In this matrix, we give a score to every project $\mathrm{P}_{\mathrm{j}}$ for each objective $\mathrm{O}_{\mathrm{o}}$, this score is called $\mathrm{s}_{\mathrm{j} o}$. This matrix shows the contribution level of projects to strategic objectives of the company. The scoring scale can be adjusted according to organizational preferences.

The management team evaluates the $s_{j o}$ with qualitative and/or normalized quantitative assessments. They also define threshold values for each

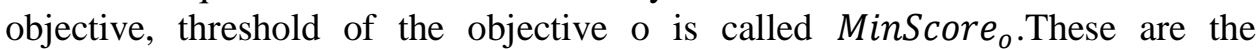
minimum objective levels that must be provided for each objective. If the minimum score of an objective is exceeded, then the portfolio is considered as aligned with this objective.

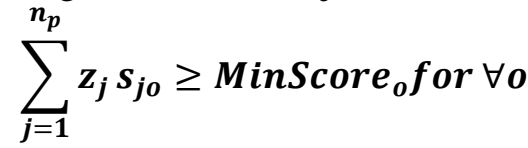


Author

\subsection{Mandatory Projects}

Finally, mandatory projects which absolutely must be in the portfolio are defined, as suggested by Stewart (1991). This would include projects with a very high importance for strategic objectives, or that may use a specific resource. In these cases, the organization cannot ignore them and the project is automatically included in the portfolio. For example, if project 1 is a mandatory project, then its corresponding binary value is 1 in the vector:

$z_{1}=1$

\section{Solving strategy}

Three previous reviews of project selection methods and models have been used and completed (Badri et al. 2001; E. W. L. Cheng and H. Li 2005; Jin Wang et al. 2009). Methods have evolved from static quantitative programming techniques to more flexible techniques such as fuzzy multi-attribute decisionmaking or fuzzy mathematical programming. The criteria are not only economical and technical, but also environmental and societal. They are evaluated not only with quantitative and measurable scales.

Our interest is the portfolio selection tools that are capable of handling interactions among project investments and resources. Cooper and co-authors highlight the fact that no existing portfolio selection method is superior in all aspects, dominant in the sense of Pareto (R. Cooper et al. 1998). They all have strengths and weaknesses in different aspects. In this study, we focus only on methods which can take into account interactions between project investments and project resources. While mathematical programming provides variability and flexibility in the problem definition, we can also model very complex interactions between projects. This is why we have chosen mathematical modelling to study interactions in this paper.

The problem is formulated as a Constraint Satisfaction Problem (CSP). It features adequate formulations of various constraints in order to satisfy the portfolio objectives. The CSP concept is often used in artificial intelligence and is suitable for many problems in different research fields such as: operational research and logic programming (Brailsford et al. 1999). With this concept, consistent assignments of the values to the variables are determined within a short period of time. A CSP is defined by a set of variables with non-empty domain sets that include possible values of each variable, and a set of constraints that involve subsets of the variables and define the allowable value combinations of the variables in the related subset (Montanari 1974).

Usually CSP solvers (e.g. IBM ILOG CP) utilize a branch and propagate and bound algorithm (Khichane et al. 2010) or branch and prune algorithm (Hentenryck et al. 1997) in order to determine consistent assignments of the variables. Assignments are generated on nodes through a search tree and if the constraint consistency is violated nodes are pruned so the related domains are filtered. Thus redundant assignments are avoided in the combinatorial problem 
and computational time is decreased. The CSP is described below with the formulation of the objective function and the description of constraints.

\section{Application to a numerical example}

In this section, a fictitious example is proposed in order to demonstrate the methodology, test its capabilities and compare the results with and without integrating project interactions. The case is introduced with its numerical data and the formulation of its constraints. The data are randomly generated, which enables to avoid confidentiality issues. Then, a computer algorithm is developed in $\mathrm{C}++$ computer language and through IBM ILOG CP Solver it is used to solve the problem.

\subsection{Numerical data}

A company wants to build a portfolio from 10 possible projects. This company cannot afford to simultaneously support more than 7 projects, because of the managerial complexity and of the difficulty in assigning project managers. They want a portfolio which has at least 3 projects, because portfolios which are too small bring too little added value to the company.

$\begin{array}{ll}\sum_{j=1}^{10} z_{j}^{k} \leq 7 & \text { for } \forall k \\ \sum_{j=1}^{10} z_{j}^{k} \geq 3 & \text { for } \forall k\end{array}$

The company has already made some investment in the machines that will be used during the execution of Project 9, so this project is considered as a mandatory project which must be in the portfolio.

$z_{9}^{k}=1 \quad$ for $\forall k$

Project 2 and Project 5 are considered as very complex projects by the top management. If at least one of them is in the portfolio, then the maximum total number of projects is 4 . As Project 2 and Project 5 are very complex projects, the company doesn't want to execute these projects together at the same time.

$$
\begin{array}{lll}
I F z_{2}^{k}=1, \text { THEN } & \sum_{j=1}^{10} z_{j}^{k} \leq 4 & \text { for } \forall k \\
I F z_{5}^{k}=1, \text { THEN } & \sum_{j=1}^{10} z_{j}^{k} \leq 4 & \text { for } \forall k \\
I F z_{2}^{k}=1, \text { THEN } & z_{2}^{k}+z_{5}^{k}=1 & \text { for } \forall k
\end{array}
$$

Project 8 is considered as moderately complex. If it is included in the portfolio, then the maximum number of the projects in the portfolio must be 5 . They do not want to execute Project 3 with Project 4 and with Project 8, because with this combination, the risk of portfolio failure increases. 
IF $z_{8}^{k}=1, T H E N \quad \sum_{j=1}^{10} z_{j}^{k} \leq 5 \quad$ for $\forall k$

IF $z_{3}^{k}=1$, THEN $\quad z_{3}^{k}+z_{4}^{k}+z_{8}^{k}=1 \quad$ for $\forall k$

Project 1 is defined as a simple project, so they want to have this project in a portfolio which has at least 4 projects.

IF $z_{1}^{k}=1$, THEN $\quad \sum_{j=1}^{10} z_{j}^{k} \geq 4 \quad$ for $\forall k$

Project 6 and Project 7 are complementary projects so they must be always together.

IF $z_{6}^{k}=1, T H E N \quad z_{6}^{k}+z_{7}^{k}=2 \quad$ for $\forall k$

IF $z_{7}^{k}=1$, THEN $\quad z_{6}^{k}+z_{7}^{k}=2 \quad$ for $\forall k$

Data showing interactions among project pairs in matrices $U^{1}, U^{2}, V^{1}, V^{2}$ and $P$ should be gathered by expertise of the management of the company before formulating the model. Data gathering is out of focus of this example. Each project uses 2 different inputs to produce 2 different outputs. $U^{i}$ is the resource interaction matrix of input $i$, for $i=1$ or $2 . V^{r}$ is the output interaction matrix of output $r, r=1$ or 2 . Resource and output matrix values are in $\mathrm{k} €$.

$\begin{aligned} U^{1} & =\left(\begin{array}{cccccccccc}10 & 0 & 0 & 0 & 0 & 0 & 0 & 0 & 0 & 0 \\ 0 & 67 & 0 & 0 & 0 & 0 & 0 & 0 & 0 & 0 \\ 0 & 0 & 37 & 0 & 0 & 0 & 0 & 0 & 0 & 0 \\ 0 & -5 & 0 & 41 & 0 & 0 & 0 & 0 & 0 & 0 \\ 0 & 0 & -10 & 0 & 118 & 0 & 0 & 0 & 0 & 0 \\ 0 & 0 & 0 & 0 & 0 & 32 & 0 & 0 & 0 & 0 \\ 0 & 0 & 0 & 0 & 0 & -3 & 24 & 0 & 0 & 0 \\ 0 & 0 & 0 & -5 & 0 & 0 & 0 & 52 & 0 & 0 \\ 0 & 0 & 0 & 0 & 0 & 0 & 0 & 0 & 38 & 0 \\ 0 & 0 & 0 & 0 & 0 & 0 & 0 & 0 & 0 & 86\end{array}\right) \\ U^{2} & =\left(\begin{array}{ccccccccccc}58 & 0 & 0 & 0 & 0 & 0 & 0 & 0 & 0 & 0 \\ 0 & 145 & 0 & 0 & 0 & 0 & 0 & 0 & 0 & 0 \\ 0 & 0 & 51 & 0 & 0 & 0 & 0 & 0 & 0 & 0 \\ 0 & -10 & 0 & 12 & 0 & 0 & 0 & 0 & 0 & 0 \\ 0 & 0 & 0 & 0 & 79 & 0 & 0 & 0 & 0 & 0 \\ 0 & 0 & -5 & 0 & 0 & 48 & 0 & 0 & 0 & 0 \\ 0 & 0 & 0 & 0 & 0 & -5 & 69 & 0 & 0 & 0 \\ 0 & 0 & 0 & 0 & 0 & 0 & 0 & 123 & 0 & 0 \\ 0 & 0 & 0 & 0 & -15 & 0 & 0 & 0 & 91 & 0 \\ -10 & 0 & 0 & 0 & 0 & 0 & 0 & 0 & 0 & 25\end{array}\right)\end{aligned}$ 
Title

$$
\begin{aligned}
& V^{I}=\left(\begin{array}{cccccccccc}
85 & 0 & 0 & 0 & 0 & 0 & 0 & 0 & 0 & 0 \\
0 & 470 & 0 & 0 & 0 & 0 & 0 & 0 & 0 & 0 \\
0 & 0 & 260 & 0 & 0 & 0 & 0 & 0 & 0 & 0 \\
0 & 0 & 0 & 240 & 0 & 0 & 0 & 0 & 0 & 0 \\
0 & 0 & 0 & 0 & 470 & 0 & 0 & 0 & 0 & 0 \\
0 & 0 & 0 & 0 & 0 & 220 & 0 & 0 & 0 & 0 \\
0 & 0 & 0 & 0 & 0 & 10 & 170 & 0 & 0 & 0 \\
0 & 0 & 0 & 20 & 0 & 0 & 0 & 510 & 0 & 0 \\
0 & 0 & 0 & 0 & 20 & 0 & 0 & 0 & 280 & 0 \\
10 & 0 & 0 & 0 & 0 & 0 & 0 & 0 & 0 & 200
\end{array}\right) \\
& V^{2}=\left(\begin{array}{cccccccccc}
120 & 0 & 0 & 0 & 0 & 0 & 0 & 0 & 0 & 0 \\
0 & 590 & 0 & 0 & 0 & 0 & 0 & 0 & 0 & 0 \\
5 & 0 & 470 & 0 & 0 & 0 & 0 & 0 & 0 & 0 \\
0 & 0 & 0 & 180 & 0 & 0 & 0 & 0 & 0 & 0 \\
0 & 0 & 10 & 0 & 620 & 0 & 0 & 0 & 0 & 0 \\
0 & 30 & 0 & 0 & 0 & 190 & 0 & 0 & 0 & 0 \\
0 & 0 & 0 & 0 & 0 & 25 & 200 & 0 & 0 & 0 \\
0 & 0 & 0 & 0 & 20 & 0 & 0 & 115 & 0 & 0 \\
0 & 30 & 0 & 0 & 0 & 0 & 0 & 0 & 370 & 0 \\
0 & 0 & 0 & 20 & 0 & 0 & 0 & 0 & 0 & 400
\end{array}\right)
\end{aligned}
$$

Projects are interdependent, which may change the probability of success if launched together. This is described in the probability of success interaction matrix $P$.

$$
P=\left(\begin{array}{cccccccccc}
0.9 & 0 & 0 & 0 & 0 & 0 & 0 & 0 & 0 & 0.05 \\
0 & 0.6 & 0 & 0 & -0.1 & 0 & 0 & 0 & 0 & 0 \\
0 & 0 & 0.7 & -0.2 & 0 & 0 & 0 & -0.2 & 0 & 0 \\
0 & 0 & 0 & 0.8 & 0 & 0 & 0 & 0 & 0 & 0 \\
0 & -0.2 & 0 & 0 & 0.65 & 0 & 0 & 0 & 0.1 & 0 \\
0 & 0 & 0.1 & 0 & 0 & 0.6 & 0.2 & 0 & 0 & 0 \\
0 & 0 & 0 & 0 & 0 & 0.23 & 0.67 & 0 & 0 & 0 \\
0 & 0 & 0 & 0 & 0 & 0 & 0 & 0.85 & 0 & 0 \\
0 & 0 & 0 & 0 & 0 & 0 & 0 & 0 & 0.8 & 0 \\
0 & 0 & 0 & 0 & 0.05 & 0 & 0 & 0 & 0 & 0.8
\end{array}\right)
$$

Resource budget of input 1 is $250 \mathrm{k} €$ and resource budget of input 2 is $350 \mathrm{k} €$

$$
\begin{array}{ll}
\sum_{j=1}^{10} z_{j}^{k} u_{j j}^{1}+\sum_{j=1}^{10} \sum_{h=j+1}^{10} z_{j}^{k} z_{h}^{k} u_{h j}^{1} \leq 250 & \text { for } \forall k \\
\sum_{j=1}^{10} z_{j}^{k} u_{j j}^{2}+\sum_{j=1}^{10} \sum_{h=j+1}^{10} z_{j}^{k} z_{h}^{k} u_{h j}^{2} \leq 350 & \text { for } \forall k
\end{array}
$$

The minimum output threshold of output 1 is $750 \mathrm{k} €$, and the minimum output threshold of output 2 is $1000 \mathrm{k} €$.

$\sum_{j=1}^{10} z_{j}^{k}\left(\sum_{l=1}^{10} z_{l}^{k} p_{j l}\right)\left[v_{j j}^{1}+\sum_{i=1}^{j-1} v_{j i}^{1} z_{i}^{k}\left(\sum_{l=1}^{10} p_{i l} z_{l}^{k}\right)\right] \geq 750 \quad$ for $\forall k$ 
$\sum_{j=1}^{10} z_{j}^{k}\left(\sum_{l=1}^{10} z_{l}^{k} p_{j l}\right)\left[v_{j j}^{2}+\sum_{i=1}^{j-1} v_{j i}^{2} z_{i}^{k}\left(\sum_{l=1}^{10} p_{i l} z_{l}^{k}\right)\right] \geq 1000 \quad$ for $\forall k$

This company has 3 main strategic objectives and they want the portfolio to be totally aligned with these objectives. They give scores scaled qualitatively from 0 to 15 to every project for each objective considering the contribution of the projects to the strategic objectives (Table 1).

For each objective, they define a minimum score threshold which must be provided by the portfolio. $s_{j o}$ is the score of the project $j\left(P_{j}\right)$ for objective $o$ $\left(O_{o}\right)$.If the sum of the scores of the projects included in the portfolio exceeds the minimum threshold, then the portfolio is aligned with the objective.

\section{Please insert Table 1 here}

The minimum score threshold for objective 1 is 15 , the minimum score threshold for objective 2 is 18 , and the minimum score threshold for objective 3 is 21 .

$\begin{array}{ll}\sum_{j=1}^{10} z_{j}^{k} s_{j 1} \geq 15 & \text { for } \forall k \\ \sum_{j=1}^{10} z_{j}^{k} s_{j 2} \geq 18 & \text { for } \forall k \\ \sum_{j=1}^{10} z_{j}^{k} s_{j 3} \geq 21 & \text { for } \forall k\end{array}$

\subsection{Results}

All the feasible different project combinations are identified. Among $2^{10}=1024$ different portfolio alternatives (for 10 projects), 14 portfolio candidates remain after the elimination of the unfeasible portfolio alternatives. The Top 5 portfolios in terms of revenue are presented in Table 2, sorted by decreasing revenue. Lastly, the portfolio which gives the biggest expected revenue is selected between the other alternatives. This portfolio \#1 gives a revenue of $1919.3 \mathrm{k} €$ and consists of: Project 1, Project 3, Project 6, Project 7, Project 9, Project 10.

\section{Please insert Table 2 here.}

Table 3 below shows the results of portfolio selection considering that the projects do not have investment interactions (Resource, Benefit \& Outcome interactions). In this case, all the off-diagonal elements of interaction matrices are equal to zero. 
In this case, 7 portfolio candidates remain after the elimination of the unfeasible portfolio alternatives. Portfolio \#5 (Project 2, Project 3, Project 9, Project 10) shows the biggest revenue (1586 k€). However, this combination gives a revenue of $1605.05 \mathrm{k} €$ in the case where the investment interactions are accounted (table 3). This should be compared with the maximum revenue of $1919.3 \mathrm{k} €$ obtained with Portfolio \#1 (table 2).

The presence of interactions changes three aspects of the decision. First, the remaining combinations are different. For instance, some savings and synergies due to simultaneous presence of some projects may permit keeping the combination under the resource constraint or over the minimal output threshold constraint, which would not have been the case considering the projects as independent. In this example; without considering project investment interactions, Portfolios \#4, 7, 9, 10, 11, 13 and 14 are screened out as unfeasible even if they are feasible in reality where interactions occur. Even a favourable portfolio (Portfolio \#1) could be screened out in different conditions.

Second, the efficiency of remaining combinations is different. This is inherent to the introduction of interactions in the objective function formulation.

Third, the decision is more reliable. Indeed, interactions are a reality. If they are not considered, as it is sometimes the case, the decision of optimal combination may be different. This involves not only a possible loss of efficiency, but more importantly a potential difference between actual and expected behaviour of the portfolio.

\section{Conclusion}

This paper addresses the challenge of building the most efficient and optimum project combination (considering their interdependencies) which meets organization's stated strategies and objectives in a desirable manner, doing so without exceeding available resources, project balance conditions or violating other constraints.

Data are basically based on expertise, and sometimes on experience (feedback on an actual past interaction between two projects). Moreover, they are basically captured bottom-up, by knowing locally for each project what its direct environment is. No systematic analysis of all the potential interdependencies with all projects for all reasons is considered for the moment. The thresholds are similarly defined by a mix of expertise and experience, but of course with unavoidable subjectivity.The presented methodology lacks also in time dimension, as it shows an instant snapshot of the portfolio and does not consider scheduling objective or constraints. Determination of the interactions is already difficult, and the expansion of the interactions definition on a time scale would be even more difficult and with a lack of reliability in the assessment. Generally, the issues of the amount of data and uncertainty associated with their assessments are important, both for data gathering, data processing and results exploitation. An important lack of reliability of the input data involves a lack of trust in the output results. These points will be studied in further research.

Finally, interactions are analysed between pairs of projects, but do not take into account the groups of projects. Interactions may change when there are 
multiple interaction sources at the same time. However, defining interactions between two projects is already a very difficult and complex process. If we try to define multiple-sided interactions, we increase the effort required for data gathering and the risk of miscalculation in data processing. Moreover, it is not necessary to measure and keep transitivity under control, like in other problems. AHP method for instance measures the experts' opinion inconsistency and compares it with the inconsistency of a randomly filled matrix. But in this case, it may be possible to have three projects $\mathrm{A}, \mathrm{B}$ and $\mathrm{C}$ with positive interactions between $\mathrm{A}$ and $\mathrm{B}$ and $\mathrm{B}$ and $\mathrm{C}$, without having positive interactions between $\mathrm{A}$ and $\mathrm{C}$. It may even be a negative interaction. It depends on the nature of the interdependence between each pair of projects.

Our methodology proposes some solutions to this complex multidimensional problem, mainly by integrating new constraints about project interdependencies in the optimization problem formulation. It looks for the optimum project portfolio alternative which has the maximum value while respecting several constraints about strategic effectiveness, efficiency and balance. It provides decision-makers with useful insights about the positive or negative effects of project combinations. It enables decisions to be closer from the reality of portfolio behaviour, since interdependencies exist. If they are not taken into account, the decision is likely to be unrealistic and different from the real evolution and performance of the portfolio.

\section{References}

Aaker, D.A. \& Tyebjee, T.T., 1978. Model for the selection of interdependent R\&D projects. IEEE Transaction on Engineering Management, 25(2), pp.30-36.

Ali, A., Kalwani, M. \& Kovenock, D., 1993. Selecting product development projects: pioneering versus incremental innovation strategies. Management Science, 39(2), pp.55-74.

Alidi, A.S., 1996. Use of the analytic hierarchy process to measure the initial viability of industrial projects. International Journal of Project Management, 14(4), pp.5-8.

Anadalingam, G. \& Olsson, C., 1989. A multi-stage multi-attribute decision model for project selection. European Journal of Operational Research, 43(2), pp.71-83.

Aragonés-Beltrán, P. et al., 2010. An ANP-based approach for the selection of photovoltaic solar power plant investment projects. Renewable and Sustainable Energy Reviews, 14(1), pp.249-264. Available at: http://linkinghub.elsevier.com/retrieve/pii/S1364032109001385 [Accessed October 11, 2012].

Bacon, C.J., 1992. The use of decision criteria in selecting information systems/technology investments. MIS Quarterly, pp.335-353.

Badri, M. a., Davis, Donald \& Davis, Donna, 2001. A comprehensive 0-1 goal programming model for project selection. International Journal of Project Management, 19(4), pp.243252. Available at: http://linkinghub.elsevier.com/retrieve/pii/S0263786399000782.

Baker, N. \& Freeland, J., 1975. Recent advances in R\&D benefit measurement and project selection methods. Management Science, 21, pp.1164-1175.

Baker, N.R., 1974. R\&D project selection model: An assessment. IEEE Transaction on Engineering Management, 21, pp.165-171.

Bardhan, I., Bagchi, S. \& Sougstad, R., 2004. Prioritizing a portfolio of information technology investment projects. Journal of Management Information Systems, 21(2), pp.33-60.

Benjamin, C.O., 1985. A linear goal programming model for public sector project selection. Journal of Operational Research Society, 36(1), pp.13-23.

Brailsford, S.C., Potts, C.N. \& Smith, B.M., 1999. Constraint satisfaction problems: algorithms and applications. European Journal of Operational Research, 119(3), pp.557-581. 
Brenner, M.S., 1994. Practical R\&D project prioritization. Research Technology Management, 37(5), pp.38-42.

Buss, M., 1983. How to rank computer projects. Harvard Business Review, 61(1), pp.18-25.

Büyüközkan, G. \& Feyzioglü, O., 2004. A fuzzy-logic based decision-making approach for new product development. International Journal of Production Economics, 90(1), pp.27-45.

Carlsson, C. et al., 2007. A fuzzy approach to R\&D project portfolio selection. International Journal of Approximate Reasoning, 44, pp.93-105.

Chen, C.-T. \& Cheng, H.-L., 2009. A comprehensive model for selecting information system project under fuzzy environment. International Journal of Project Management, 27(4), pp.389-399. Available at: http://linkinghub.elsevier.com/retrieve/pii/S0263786308000537 [Accessed April 8, 2013].

Chen, K. \& Gorla, N., 1998. Information system project selection using fuzzy logic. IEEE Transactions on Systems Management Cybernetics - Part A, 28(6), pp.49-55.

Cheng, E.W.L. \& Li, H., 2005. Analytic network process applied to project selection. Journal of Construction Engineering and Management, 131(4), pp.59-66.

Coffin, M.A. \& Taylor, B.W., 1996. Multiple criteria R\&D project selection and scheduling using fuzzy logic. Computers \& Operations Research, 23(3), pp.207-220.

Conka, T., Vayvay, O. \& Sennaroglu, B., 2008. A combined decision model for R\&D project portfolio selection. International Journal of Business Innovation and Research, 2(2), pp.190 $-202$.

Cooper, R., Edgett, E.S. \& Kleinschmidt, E., 1998. Best Practices for Managing R\&D Portfolios. Research Technology Management, 41(4).

Cooper, R.G., Edgett, E.S. \& Kleinschmidt, E., 1997. Portfolio Management in New Product Development: Lessons from the Leaders-I. Research Technology Management, 40(5), pp.16-19.

Cooper, R.G., Edgett, S.J. \& Kleinschmidt, E.J., 1998. Portfolio Management for New Products, Reading, Massachusetts: Perseus Books.

Cooper, R.G., Edgett, S.J. \& Kleinschmidt, E.J., 1997. Portfolio Management in New Product Development: Lessons from the Leaders-II. Research Technology Management, pp.43-52.

Czajkowski, A. \& Jones, S., 1986. Selecting interrelated R\&D projects in space technology planning. IEEE Transactions on Engineering Management, 33(1), pp.17-24.

Danila, N., 1989. Strategic evaluation and selection of R\&D projects. $R \& D$ Management, 19, pp.47-62.

Dey, P.K., 2006. Integrated project evaluation and selection using multiple-attribute decisionmaking. International Journal of Production Economics, 103, pp.90-103.

Dickinson, M.W., Thornton, A.C. \& Graves, S., 2001. Technology portfolio management: Optimizing interdependent projects over multiple time periods. IEEE Transaction on Engineering Management, 48, pp.518-527.

Doumpos, M. et al., 2009. An evolutionary approach to construction of outranking models for multicriteria classification: the case of the ELECTRE TRI method. European Journal of Operational Research, 199, pp.496-505.

Eilat, H., Golany, B. \& Shtub, A., 2006. Constructing and evaluating balanced portfolios of R\&D projects with interactions: A DEA based methodology. European Journal of Operational Research, 172(3), pp.1018-1039. Available at: http://linkinghub.elsevier.com/retrieve/pii/S0377221705000068 [Accessed October 26, 2012].

Figueira, J., Greco, S. \& Roy, B., 2009. ELECTRE methods with interaction between criteria: An extension of the concordance index. European Journal of Operational Research, 199, pp.478-495.

Floricel, S. \& Ibanescu, M., 2008. Using R\&D portfolio management to deal with dynamic risk. $R \& D$ Management, 38(5), pp.452-467. Available at: http://onlinelibrary.wiley.com/doi/10.1111/j.1467-9310.2008.00535.x/pdf.

Fox, G.E., Baker, N.R. \& Bryant, J.L., 1984. Economic models for R\&D project selection in the presence of project interactions. Management Science, 30, pp.890-902. 


\section{Author}

Gear, T.E. \& Cowie, G.C., 1980. A note on modeling project interdependence in research and development. Decision Sciences, 11, pp.738-748.

Gerogiannis, V.C. et al., 2010. A case study for project and portfolio management information system selection: a group AHP-scoring model approach. International Journal of Project Organisation and Management, 2(4), pp.361 - 381.

Ghapanchi, A.H. et al., 2012. A methodology for selecting portfolios of projects with interactions and under uncertainty. International Journal of Project Management, 30(7), pp.791-803. Available at: http://linkinghub.elsevier.com/retrieve/pii/S0263786312000142 [Accessed February 28, 2013].

Ghasemzadeh, F., 1998. Project portfolio selection: A decision support approach.,

Gori, E., 1996. Portfolio selection of capital investment projects in the Durban metropolitan region. Construction Management Economics, 14, pp.1-6.

Groenveld, 1997. Roadmapping integrates business and technology. Research Technology Management, 40, pp.48-55.

Guimaraes, T. \& McKeen, J., 1988. Organizational bias in the selection of MIS projects. Omega, 1, pp.297-307.

Gustafsson, J. \& Salo, A., 2005. Contingent Portfolio Programming of Risky Projects. Operations Research, 53(6), pp.946-956.

Hall, L. \& Nauda, A., 1990. An interactive approach for selecting R\&D projects. IEEE Transaction on Engineering Management, 37(2), pp.26-33.

Henriksen, A.D. \& Traynor, A.J., 1999. A practical R\&D project-selection scoring tool. IEEE Transaction on Engineering Management, 46, pp.158-170.

Hentenryck, P.V., McAllester, D. \& Kapur, D., 1997. Solving Polynomial Systems Using a Branch and Prune Approach. SIAM Journal on Numerical Analysis, 34(2), pp.797-827.

Hess, S., 1993. Swinging on a branch of a tree: project selection application. Interfaces, 39(2), pp.55-74.

Huang, C.C., Chu, P.Y. \& Chiang, Y.H., 2008. A fuzzy AHP application in government-sponsored R\&D project selection. Omega, 36(6), pp.1038-1052.

Huang, X., 2007. Optimal project selection with random fuzzy parameters. International Journal of Production Economics, 106(5), pp.13-22.

Hwang, G. \& Yoon, K., 1981. Multiple attributes decision-making methods and applications, New York: Springer.

Iyigun, M., 1993. A decision support system for $R \& D$ project selection and resource allocation under uncertainty. Project Management Journal, 24, pp.5-13.

Jiang, J.J. \& Klein, G., 1999. Information system project selection criteria variations within strategic classes. IEEE Transaction on Engineering Management, 46(2), pp.1-6.

Kerzner, H., 2004. Advanced project management - Best practices on implementation., 2nd ed. John Wiley \& Sons.

Kester, L. et al., 2011. Exploring portfolio decision-making processes. Journal of Product Innovation Management, 28, pp.641-661.

Al Khalil, M., 2002. Selecting the appropriate project delivery method using AHP. International Journal of Project Management, 20(4), pp.69-74.

Khichane, M., Albert, P. \& Solnon, C., 2010. Strong Combination of Ant Colony Optimization with Constraint Programming Optimization. In CPAIOR. pp. 232-245.

Khorramshahgol, R., Azani, H. \& Gousty, Y., 1988. An integrated approach to project evaluation and selection. IEEE Transaction on Engineering Management, 35(2), pp.65-70.

Killen, C.P. et al., 2012. Advancing project and portfolio management research: Applying strategic management theories. International Journal of Project Management, 30(5), pp.525-538. Available at: http://linkinghub.elsevier.com/retrieve/pii/S026378631200004X [Accessed October 9, 2012].

Killen, C.P., 2012. Evaluation of project interdependency visualizations through decision scenario experimentation. International Journal of Project Management. Available at: http://linkinghub.elsevier.com/retrieve/pii/S0263786312001111 [Accessed March 18, 2013]. 
Lee, J.W. \& Kim, S.H., 2001. An integrated approach for interdependent information system project selection. International Journal of Project Management, 19(2), pp.111-118. Available at: http://linkinghub.elsevier.com/retrieve/pii/S0263786399000538.

Lee, S., 1972. Goal programming for decision-making, Philadelphia: Auerbach.

Liberatore, M.J., 1987. An extension of the analytic hierarchy process for industrial R\&D project selection and resource allocation. IEEE Transaction on Engineering Management, 34(1), pp.2-8.

Liberatore, M.J. \& Titus, G.J., 1983. The practice of management science in R\&D project management. Management Science, 29, pp.962-975.

Liesiö, J., Mild, P. \& Salo, A., 2007. Preference Programming for Robust Portfolio Modeling and Project Selection. European Journal of Operational Research, 181, pp.1488-1505.

Liesiö, J., Mild, P. \& Salo, A., 2008. Robust Portfolio Modeling with Incomplete Cost Information and Project Interdependencies. European Journal of Operational Research, 190, pp.679695.

Lin, C.H. \& Hsieh, P.J., 2004. A fuzzy decision support system for strategic portfolio management. Decision Support Systems, 38(3), pp.383-398.

Lockett, A.G. \& Gear, A.E., 1973. Representation and Analysis of Multi-Stage Problems in R\&D. Management Science, 19(8), pp.947-960.

Lootsma, F., Mensch, T. \& Vos, F., 1990. Multi-criteria analysis and budget reallocation in longterm research planning. European Journal of Operational Research, 47(3), pp.293-305.

Lucas, H. \& Moore, J., 1976. A multiple-criterion scoring approach to information system project selection. Information, 14(1), pp.1-12.

Machacha, L.L. \& Bhattacharya, P., 2000. A fuzzy logic-based approach to project selection. IEEE Transaction on Engineering Management, 47(1), pp.65-73.

Mahmoodzadeh, S. et al., 2007. Project Selection by Using Fuzzy AHP and TOPSIS Technique,

Maylor, H. et al., 2006. From projectification to programmification. International Journal of Project Management, 24, pp.663-674.

McKeen, J. \& Guimaraes, T., 1985. Selecting MIS projects by steering committee. Communications of the ACM, 28(13), pp.44-52.

Meade, L.M. \& Presley, A., 2002. R\&D project selection using the analytic network process. IEEE Transaction on Engineering Management, 49(1), pp.59-66.

Melone, N.P. \& Wharton, T.J., 1984. Strategies for MIS project selection. Journal of Systems Management, 6(2), pp.26-33.

Mikkola, J.H., 2001. Portfolio management of R\&D projects: Implications for innovation management. Technovation, 21(7), pp.423-435. Available at: http://linkinghub.elsevier.com/retrieve/pii/S0166497200000626.

Mohanty, R.P., 1992. Project selection by a multiple-criteria decision-making method: an example from a developing country. International Journal of Project Management, 10(1), pp.1-8.

Molenaar, K.R. \& Songer, A.D., 1998. Model for public sector design-build project selection. Journal of Construction Engineering and Management, 124(6), pp.67-79.

Montanari, U., 1974. Networks of Constraints: Fundamental Properties and Applications to Picture Processing. Information Sciences, 7, pp.95-132.

Moore, J. \& Baker, N.R., 1969. An analytical approach to scoring model design - application to $\mathrm{R} \& \mathrm{D}$ project selection. IEEE Transaction on Engineering Management, 16(3), pp.1-8.

Muralidhar, K., Santhanam, R. \& Wilson, R., 1990. Using the analytic hierarchy process for information system project selection. Information \& Management, 18(1), pp.87-95.

Nemhauser, G. \& Ullmann, Z., 1969. Discrete dynamic programming and capital allocation. Management Science, 15(9), pp.494-505.

Odusote, O.O. \& Fellows, R.F., 1992. An examination of the importance of resource considerations when contractors make project selection decisions. Construction Management Economics, 10(1), pp.37-51.

Okpala, D.C., 1991. Evaluation and selection of construction projects in Nigeria. Construction Management Economics, 9, pp.51-61. 
Author

Petit, Y., 2012. Project portfolios in dynamic environments: Organizing for uncertainty. International Journal of Project Management, 30(5), pp.539-553. Available at: http://linkinghub.elsevier.com/retrieve/pii/S0263786311001530 [Accessed March 17, 2013].

Pillai, A.S., Joshi, A. \& Rao, K.S., 2002. Performance measurement of R\&D projects in a multiproject, concurrent engineering environment. International Journal of Project Management, 20(1), pp.65-77.

Ravanshadnia, M., Rajaie, H. \& Abbasian, H.R., 2010. Hybrid fuzzy MADM project-selection model for diversified construction companies. Canadian Journal of Civil Engineering, 37(8), pp.1082-1093.

Reiter, S., 1963. Choosing an investment program among interdependent projects. Review of Economic Studies, 30(2), pp.2-6.

Riddell, S. \& Wallace, W.A., 2011. The use of fuzzy logic and expert judgment in the R\&D project portfolio selection process. International journal of technology management, 53(2-3-4), pp. $238-256$.

Ringuest, J. \& Graves, S., 1989. The linear multi-objective R\&D project selection problem. IEEE Transaction on Engineering Management, 36(1), pp.4-7.

Roy, B., 1991. The outranking approach and the foundations of ELECTRE methods. Theory and Decision, 31(1), pp.49-73.

Saaty, T., 1980. The Analytic Hierarchy Process: Planning, Priority Setting, Resource Allocation, McGraw-Hill.

Saaty, T.L., 2001. Models, Methods, Concepts \& Applications of the Analytic Hierarchy Process, with Luis G. Vargas, Kluwer Academic.

Santhanam, R. \& Kyparisis, G., 1996. A decision model for interdependent system project selection. European Journal of Operational Research, 89(3), pp.80-99.

Santhanam, R. \& Kyparisis, G., 1995. A multiple criteria decision model for information system project selection. Computers \& Operations Research, 22(8), pp.07-18.

Santhanam, R., Muralidhar, K. \& Schniederjans, M., 1989. A zero-one goal programming approach for information system project selection. Omega, 17(6), pp.83-93.

Santhanam, R. \& Schniederjans, M., 1993. A model and formulation system for information system project selection. Computers \& Operations Research, 20(7), pp.55-67.

Schmidt, R.L., 1993. A model for R\&D project selection with combined benefit, outcome and resource interactions. IEEE Transaction on Engineering Management, 40, pp.403-410.

Schniederjans, M. \& Santhanam, R., 1993. A multi-objective constrained resource information system project selection method. European Journal of Operational Research, 70(2), pp.4453.

Schniederjans, M. \& Wilson, R., 1991. Using the analytic hierarchy process and goal programming for information system project selection. Information \& Management, 20(3), pp.33-42.

Shoval, P. \& Luhasi, Y., 1987. Models for computer system evaluation and selection. Information \& Management, 12(2), pp.17-29.

Skitmore, M., Drew, D.S. \& Ngai, S., 2001. Bid-spread. Journal of Construction Engineering and Management, 127(2), pp.49-53.

Stewart, T., 1991. A multi criteria decision support system for R\&D project selection. Journal of the Operational Research Society, 42, pp.17-26.

Sun, H. \& Ma, T., 2005. A packing-multiple-boxes model for R\&D project selection and scheduling. Technovation, 25(11), pp.1355-1361. Available at: http://linkinghub.elsevier.com/retrieve/pii/S0166497204001166 [Accessed October 11, 2012].

Thiry, M. \& Deguire, M., 2007. Recent developments in project-based organizations. International Journal of Project Management, 25, pp.649-658.

Tiryaki, F. \& Ahlatcioglu, B., 2009. Fuzzy portfolio selection using fuzzy analytic hierarchy process. Information Sciences, 179(1-2), pp.53-69.

Tiryaki, F. \& Ahlatcioglu, B., 2005. Fuzzy stock selection using a new fuzzy ranking and weighting algorithm. Applied Mathematics and Computation, 170(1), pp.144-157.

Ullmann, Z., 1967. Dynamic programming and the capital allocation problem. The John Hopkins University. 
Wang, J. \& Hwang, W.L., 2007. A fuzzy set approach for R\&D portfolio selection using a real options valuation model. Omega, 35, pp.247-257.

Weber, R., Werners, B. \& Zimmerman, H., 1990. Planning Models for Research and Development. European Journal of Operational Research, 48(1), pp.75-88.

Weingartner, H.M., 1966a. Capital budgeting of interrelated projects: survey and synthesis. Management Science, 12, pp.485-516.

Weingartner, H.M., 1966b. Criteria for programming investment project selection. Journal of Industrial Economics, 11, pp.65-76.

Wong, E.T.T., Norman, G. \& Flanagan, R., 2000. A fuzzy stochastic technique for project selection. Construction Management Economics, 18, pp.7-14.

Xidonas, P. et al., 2009. Portfolio engineering using the IPSSIS multiobjective optimisation decision support system. International Journal of Decision Sciences, Risk and Management, 1(1-2), pp.36-53.

Zhu, D. et al., 2009. Developing an R\&D projects portfolio selection decision system based on fuzzy logic. International Journal of Modelling, Identification and Control, 8(3), pp.205 212. 


\section{Author}

Table 1 Scores of the projects for each objective

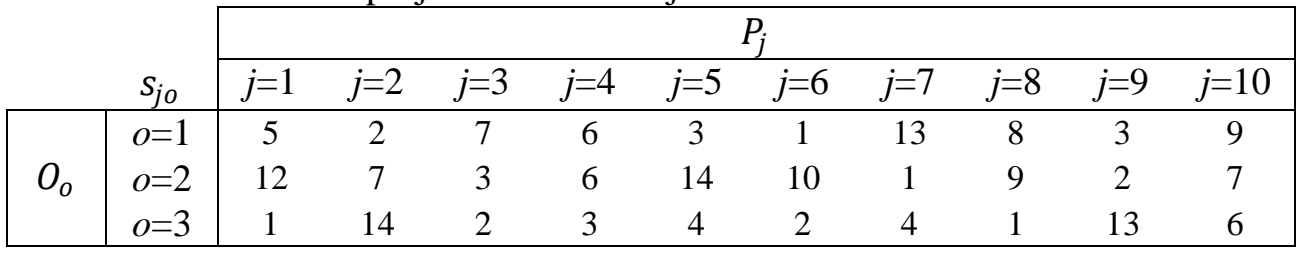


Title

Table 2Results when interactions are considered

\begin{tabular}{|c|c|c|c|c|c|c|c|c|c|}
\hline \multirow{2}{*}{ Portfolios } & \multirow{2}{*}{$\begin{array}{l}\mathrm{Nb} \text { of } \\
\text { Projects }\end{array}$} & \multirow{2}{*}{\multicolumn{2}{|c|}{$\begin{array}{l}\text { InputInput } \\
1 \quad 2\end{array}$}} & \multirow{2}{*}{\multicolumn{3}{|c|}{ Obj1Obj2Obj3 }} & \multirow{2}{*}{\multicolumn{2}{|c|}{$\begin{array}{l}\text { OutputOutput } \\
1\end{array}$}} & \multirow{2}{*}{ Revenue } \\
\hline & & & & & & & & & \\
\hline \#1 & 6 & 224 & 322 & 38 & 35 & 28 & 1049 & 1454 & 1919.3 \\
\hline$\# 2$ & 5 & 214 & 274 & 33 & 23 & 27 & 968 & 1325 & 1772.35 \\
\hline \#3 & 6 & 228 & 288 & 37 & 38 & 29 & 1031 & 1248 & 1725.6 \\
\hline \#4 & 4 & 244 & 290 & 20 & 31 & 21 & 1202 & 1003 & 1650.75 \\
\hline \#5 & 4 & 228 & 312 & 21 & 19 & 35 & 863 & 1303 & 1605.05 \\
\hline
\end{tabular}




\section{Author}

Table 3Results when interactions are not considered

\begin{tabular}{llllllllll}
\hline \multirow{2}{*}{ Portfolios } & Nb of & \multicolumn{3}{l}{ InputInput } & \multicolumn{4}{c}{ Obj1Obj2Obj3 } & \multicolumn{3}{c}{ OutputOutput } & \multirow{2}{*}{ Revenue } \\
& Projects & 1 & 2 & & & & 1 & 2 & \\
\hline$\# 5$ & 4 & 228 & 312 & 21 & 19 & 35 & 848 & 1299 & 1586 \\
$\# 1$ & 6 & 227 & 342 & 38 & 35 & 28 & 888 & 1301 & 1582,4 \\
$\# 2$ & 5 & 217 & 284 & 33 & 23 & 27 & 812 & 1193 & 1470,9 \\
$\# 8$ & 4 & 232 & 273 & 20 & 22 & 36 & 858 & 1114 & 1447 \\
$\# 3$ & 6 & 231 & 303 & 37 & 38 & 29 & 898 & 1116 & 1443,4 \\
\hline
\end{tabular}

